\title{
Heat, hostility, and immune function: The moderating effects of gender and demand characteristics
}

\author{
SUSAN DUBITSKY, RUTH WEBER, and JAMES ROTTON \\ Florida International University, Miami, Florida
}

\begin{abstract}
It was hypothesized that demand characteristics are responsible for relations between heat and hostility in laboratory experiments. This hypothesis was tested by leading 28 males and 28 females to believe that heat would have either positive or negative effects and then exposing them to either moderately or very high temperatures. As hypothesized, the subjects who were led to expect negative effects from heat exposure expressed more hostility and evidenced less positive affect than those who were led to expect positive effects. In addition, higher levels of secretory immunoglobulin A were found in the saliva of the males when heat was portrayed in threatening rather than beneficial terms.
\end{abstract}

Recent studies have investigated the possibility that demand characteristics are responsible for effects frequently attributed to environmental manipulations. Knasko, Gilbert, and Sabini (1990), for example, found that subjects felt more positive and experienced fewer physical symptoms when they were led to believe that they had been exposed to a pleasant odor that was, in fact, not present. Similar results have been obtained in research on fullspectrum lighting (Veitch, Gifford, \& Hine, 1991) and color (Smith, Bell, \& Fusco, 1986).

Anderson and Anderson (1984) suggested that demand characteristics might be responsible for results obtained in laboratory studies on heat and aggression. In their view, heat is such a salient and unusual property of a laboratory setting that the subjects guessed that the experimenters were interested in the effects of temperature. This view is supported by results from field experiments (Rotton, Shats, \& Standers, 1990; Standers, Rotton, \& Schlossberg, 1992). Rotton and colleagues found that although naive subjects walked faster in warm than in cool settings, they did not evidence awareness of psychological states, which are supposed to mediate relations between heat and behavior. These findings led us to hypothesize that subjects would evidence negative affect if they were exposed to heat under threatening conditions, but would evidence positive affect if similar levels of heat were portrayed as part of a positive (i.e., sauna) environment.

The present experiment's second and more exploratory goal was to assess the effects of heat on salivary immunoglobulin A (SIgA), which has been described as the body's

This research was supported by a faculty development grant to the third author from Florida International University. We would like to thank Ray Galleno, Michael Glixman, Lynn Herndon, Kathy Sardinhia, and Doris Wainwright for their assistance in collecting data. Address correspondence to S. Dubitsky, Psychology Department, Florida International University, North Miami, FL 33181. first line of defense against upper respiratory illness (Jemmott \& McClelland, 1989). It was expected that SIgA levels would be affected by beliefs about heat rather than actual temperature. This expectation was based, in part, on the fact that temperature did not attain significance in a recent study (Housh, Johnson, Housh, Evans, \& Tharp, 1991) on the combined effects of temperature and exercise. It was also based on the fact that Mason et al. (1976) found that even temperatures over $37.78^{\circ} \mathrm{C}$ did not increase stress hormones (e.g., 17-OCHS and cortisol) when heat was introduced in a gradual, nonthreatening manner.

\section{METHOD}

\section{Subjects}

Fifty-eight psychology students received course credit for participating in the experiment, whose procedures had been approved by the university's institutional review board. Two female students withdrew after being informed that they would be exposed to heat, leaving 28 males and 28 females whose ages ranged from 18 to 53 years $(M=$ 26.84; $S D=8.06$ ).

\section{Setting}

The subjects were tested in one of two rooms, each of which measured $1.68 \times 2.76 \mathrm{~m}$. The room used for encouraging positive expectations was built out of wood slats to resemble a sauna. It contained a portable heater housed in a wood casing that was covered with artificial briquettes. A sign with the word SAUNA in large $(2.58 \mathrm{~cm})$ capital letters was on the door. The room used for encouraging negative expectations was furnished with a single chair, a white table, and two portable heaters. The equally large sign on its door read HEAT STRESS CHAMBER.

\section{Procedure}

After having the subjects sign the first of two sheets for informed consent, a female experimenter used a monitor (Labtron, Graham-Field, Inc., Hauppauge, NY) to obtain baseline readings of systolic and diastolic blood pressure. She then asked the subjects to complete Watson, Clark, and Tellegen's (1988) Positive and Negative Affect Schedule (PANAS). Afterward, she requested that the subjects drool into a paper cup while chewing on a piece of paraffin wax until $5 \mathrm{ml}$ of saliva 
had been collected (Dubitsky, Weber, \& Rotton, 1993). The saliva was then transferred into a graduated test tube, which was sealed, labeled, and immediately placed on ice. Saliva samples were stored at $-20^{\circ} \mathrm{C}$ until assays were performed. The date and time of collection were recorded for use as covariates in data analyses.

Expectation. A second informed consent sheet was used to reinforce beliefs about the positive or negative effects of heat. The sheet informed the subjects that they would be exposed to a level of temperature that had been found to produce either positive or negative effects in previous research. This manipulation was strengthened by asking the subjects to read one of two articles. The article in the positive-expectation condition was entitled "Some Like it Hot." This article, which was excerpted from a book by Ornstein and Sobel (1989, pp. 46-68), described the positive benefits of taking a sauna. The article in the negative condition, which was entitled "Some Don't Like it Hot," was portrayed as having been reprinted from the New York Times. It emphasized the negative effects (e.g., stroke, exhaustion) of high temperatures. ${ }^{1}$

Temperature. After the subjects read the article and their blood pressure had been recorded again, they were asked to supply a second sample of saliva and then step into one of the experimental chambers. The rooms had been preheated to have target temperatures of $29.4^{\circ}$ and $37.8^{\circ} \mathrm{C}$ (moderately warm and hot). Recordings before and after each session indicated that the rooms' temperatures were nearly on target $\left[M=28.85^{\circ}\right.$ vs. $\left.38.41^{\circ} \mathrm{C} ; t(54)=39.18, p<.01\right]$. Physiological measures (i.e., blood pressure and saliva) were collected for a third time after the subjects had sat in the sauna for $10 \mathrm{~min}$. They were then handed a packet that contained the following measures: a posttest version of the PANAS, a measure of hostility (Anderson, 1990), Pennebaker's (1982) Symptom Checklist, and the Perceived Environmental Quality Index (PEQI), which has been used to evaluate interior and outdoor settings (Rotton et al., 1990).

\section{Assay}

Frozen saliva samples were thawed and assayed by using the radial immunodiffusion method (Endoplate, Kallestad Laboratories, Inc., Austin, TX). Five microliters of saliva from each subject and three reference sera were pipetted into 16-well agar plates, which contained a monospecific antiserum. The resulting precipitin rings, caused by SIgA diffusion through the plates, were measured by two different raters after a 48-h incubation period. The average Pearson correlation for interrater reliability was $r=.75$.

\section{RESULTS}

\section{Check on Manipulation}

The subjects reported feeling warmer in the hot than in the moderately warm room $[M \mathrm{~s}=6.63$ vs. 4.93 ; $F(1,53)=36.82, p<.001]$. The subjects exposed to the high temperature also reported more symptoms than those exposed to the moderately high temperature $[M=$ 19.29 vs. $15.45 ; F(1,48)=5.43, p<.05]$. An analysis of the individual items on the symptom scale disclosed that this significant effect stemmed from reliable differences in reported severity of watery eyes $(p<.05)$, flushed face $(p<.05)$, shortness of breath $(p<.05)$, and dizziness $(p<.05)$.

\section{Verbal Ratings}

Expectancy was the only variable whose effect approached significance $[F(3,44)=2.33, p<.09]$, in a multivariate analysis of covariance (MANCOVA) that controlled for preexperimental ratings of positive and negative affect. Univariate tests indicated that the subjects in the sauna condition reported more positive affect than those in the heat chamber [adjusted $M \mathrm{~s}=28.67$ vs. $27.11 ; F(1,47)=4.28, p<.05]$. There was also a slight but not statistically significant tendency for less negative affect to be reported by the subjects in the sauna than by those in the heat chamber [adjusted $M \mathrm{~s}=11.76$ vs. $13.31 ; F(1,47)=3.54, p<.07$ ]. In addition, as hypothesized, the subjects in the heat chamber verbalized higher levels of hostility than those in the sauna $[M \mathrm{~s}=75.95$ vs. $64.75 ; F(1,48)=4.33, p<.05]$.

\section{Physiological Measures}

Preliminary multivariate analyses disclosed that initial levels of systolic and diastolic blood pressure were higher for the males than for the females $[F(2,47)=29.99, p<$ $.01]$. Because these analyses also indicated that nearly identical levels of blood pressure were obtained during the second and third time periods, the latter readings were averaged. Gender was the only factor that attained significance in an ANCOVA on diastolic readings $[F(1,47)$ $=8.78, p<.01]$. Higher levels were recorded for the males than the females (adjusted $M s=76.84$ vs. 61.82) in analyses that controlled for initial readings. Gender also attained significance in an ANCOVA on systolic readings $[F(1,47)=4.48, p<.05]$, but this main effect was qualified by gender's interaction with room temperature $[F(1,47)=4.28, p<.05]$. Post hoc tests indicated that the blood pressure of the females in the moderately warm room $(M=105.34)$ was lower than that of the females in the hot room $(M=112.47)$ and the males in either the hot or the warm rooms $(M s=114.49$ and 116.41 , $p<.01$ by Bonferroni $t$ test).

Gender also interacted with expectancies in an analysis of the second and third SIgA readings $[F(1,48)=$ $6.74, p<.05]$. This interaction retained its significance in analyses that controlled for preexperimental differences in $\operatorname{SIgA}[F(1,47)=5.64, p<.05]$. Figure 1 shows that the SIgA levels of the females were slightly but not significantly higher when expectancies were positive $[F(1,47)$

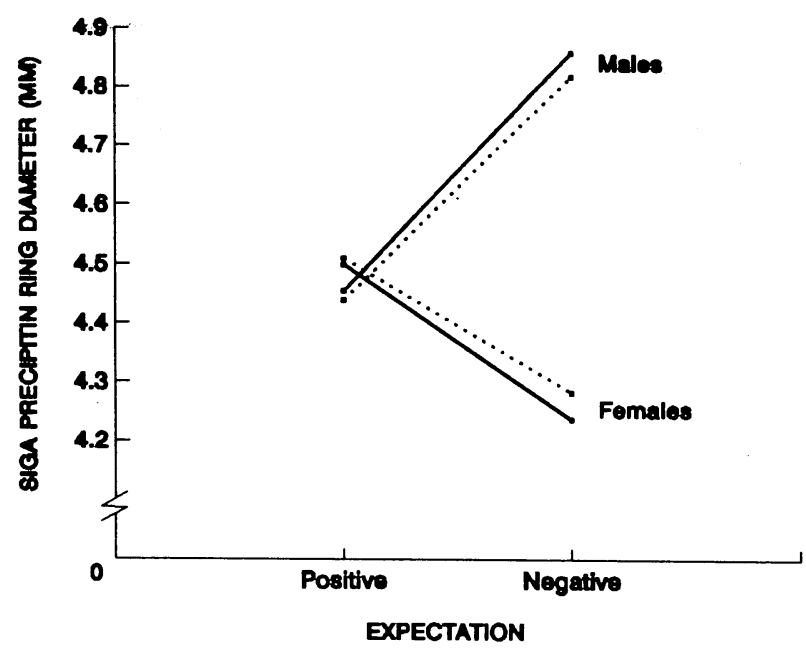

Figure 1. Observed (solid line) and covariate-adjusted (dashed line) levels of secretory immunoglobulin A (SIgA) as a function of gender and expectation. 
$=1.67, p<.25]$, and the SIgA levels of the males were significantly higher when they expected the effects of heat to be negative $[F(1,47)=4.47, p<.05]$.

\section{DISCUSSION}

The present results implicate demand characteristics as a potential confound in research on the effects of high temperature. It is possible that manipulation of ambient temperature would have also attained significance if the experimental conditions had been compared with normal or comfortable levels of temperature, but it is unlikely that the subjects would have believed that they were in a sauna or heat chamber if they had been exposed to typical $\left(22.2^{\circ} \mathrm{C}\right)$ levels of indoor temperature. The results are also limited by the fact that the experiment's principal dependent variable was verbal rather than physical aggression. Despite these limitations, the results suggest that investigators employing paperand-pencil measures of hostility should include Orne's (1969) placebo control group to assess the effects of demand characteristics. They also suggest that future research on heat should focus on determining whether demand characteristics are responsible for results obtained in studies that have employed physical measures of aggression, such as shock intensity.

Expectancies also interacted with gender to affect levels of SIgA. As expected, SIgA levels were slightly (but not significantly) higher when the females were led to view heat as a positive rather than a negative experience. Contrary to our expectations, however, the males' SIgA levels were higher when heat was portrayed in negative rather than in positive terms; it is possible that the males interpreted the heat as a challenge. Consistent with this possibility, subsidiary analyses indicated that responses to the positive adjectives on the PANAS were correlated with SIgA levels (total and within-cell $r s=.28$ and $.243, p<.05$ ]. However, it should be cautioned that scores on the other two paperand-pencil measures of emotion (negative affect and hostility) were not correlated with SIgA levels. It should also be noted that some researchers (Stone, Cox, Valdimarsdottir, \& Neale, 1987) have argued that assays should include controls for volume and flow rate of saliva, but Jemmott and McClelland (1989) have presented results from a meta-analysis, which suggests that such controls increase the significance of results from situational manipulations.

\section{REFERENCES}

ANDERSON, C. A. (1990). Effects of hot temperature on arousal and hostility. Unpublished manuscript, University of Missouri, Columbia.

Anderson, C. A., \& ANDERson, D. C. (1984). Ambient temperature and violent crime: Test of the linear and curvilinear hypotheses. Journal of Personality \& Social Psychology, 46, 91-97.

Dubitsky, S., Weber, R., \& Rotron, J. (1993, June). Collection of saliva samples for biochemical assays: $A$ comparison of methods. Paper presented at the Convention of the American Psychological Society, Chicago.
Housch, T. J., Johnson, G. O., Housch, D. J., Evans, S. L., \& THARP, D. J. (1991). The effects of exercise at various temperatures on salivary levels of immunoglobulin A. International Journal of Sports Medicine, 12, 498-500.

Jemmott, J. B. I., \& McClelland, D. C. (1989). Secretory IgA as a measure of resistance to infectious disease: Comments on Stone, Cox, Valdimarsdottir, and Neale. Behavioral Medicine, 15, 63-71.

Knasko, S. C., Gilbert, A. N., \& SABINI, J. (1990). Emotional state, physical well-being, and performance in the presence of feigned ambient odor. Journal of Applied Social Psychology, 16, 1345-1357.

Mason, J. W., Maher, J. T., Hartley, L. H., Mougey, E. H., PerLOW, M. J., \& JoNES, L. G. (1976). Selectivity of corticosteroid and catecholamine responses to various natural stimuli. In G. Serban (Ed.), Psychopathology of human adaptation (pp. 147-171). New York: Plenum.

ORNE, M. T. (1969). Demand characteristics and the concept of quasicontrol. In R. Rosenthal \& R. L. Rosnow (Eds.), Artifact in behavioral research (pp. 143-179). New York: Academic Press.

ORNSTEIN, R., \& SOBEL, D. (1989). Healthy pleasures. Reading, MA: Addison-Wesley.

PenNebaKer, J. W. (1982). The psychology of physical symptoms. New York: Springer-Verlag.

Rotton, J., Shats, M., \& Standers, R. (1990). Temperature and pedestrian tempo: Walking without awareness. Environment \& Behavior, 22, 650-674.

Smith, J. M., Bell, P. A., \& Fusco, M. E. (1986). The influence of color and demand characteristics on muscle strength and affective ratings of the environment. Journal of General Psychology, 113, 289-297.

StANDERS, R., RotTon, J., \& Schlossberg, R. (1992). Effects of heat and cognitive demands on ambulatory movement. In E. M. Starnes \& J. M. Stein (Eds.), "I can't get there from here": Symposium on walking and bicycling issues (pp. 112-122). Gainesville, FL: University of Florida.

Stone, A. A., Cox, D. S., Valdimarsdottir, H., \& Neale, J. M. (1987). Secretory IgA as a measure of immunocompetence. Journal of Human Stress, 13, 136-140.

Veitch, J. A., Gifford, R., \& Hine, D. W. (1991). Demand characteristics and full spectrum lighting effects on performance and mood. Journal of Environmental Psychology, 11, 87-95.

Watson, D., Clark, L. A., \& Tellegen, A. (1988). Development and validation of brief measures of positive and negative affect: The PANAS scales. Journal of Personality \& Social Psychology, 54, 1063-1070.

\section{NOTE}

1. A copy of this fictitious article may be obtained from the first author.

(Manuscript received June 10, 1993.) 